\title{
Patient Satisfaction With Care for Urgent Health Problems: A Survey of Family Practice Patients
}

\author{
Michelle Howard, MSc, PbD ${ }^{1}$ \\ James Goertzen, MD, MCLSC, \\ CCFP, FCFP 1,2 \\ Brian Hutchison, MD, MSc, FCFP $P^{1,3}$ \\ Janusz Kaczorowski, $P b D^{1}$ \\ Kelly Morris, $\mathrm{BSc}^{1}$ \\ ${ }^{1}$ Department of Family Medicine, McMaster \\ University, Hamilton, Ontario, Canada \\ ${ }^{2}$ Northern Ontario School of Medicine, \\ Thunder Bay, Ontario, Canada \\ ${ }^{3}$ Center for Health Economics and Policy \\ Analysis, McMaster University, Hamilton, \\ Ontario, Canada

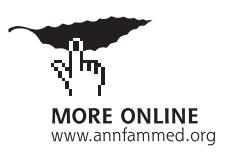

Conflicts of interest: none reported

\section{CORRESPONDING AUTHOR}

Michelle Howard, MSc, PhD Department of Family Medicine McMaster University 75 Frid $\mathrm{St}$

Hamilton, ON L8P $4 \mathrm{M} 3$

mhoward@mcmaster.ca

\begin{abstract}
PURPOSE Patient satisfaction is an important health care outcome. This study compared patients' satisfaction with care received for an urgent health problem from their family physician, at an after-hours clinic in which their physician participated, at a walk-in clinic, at the emergency department, from telephone health advisory services, or from more than 1 of those services.
\end{abstract}

METHODS We mailed a questionnaire to a random sample of patients from 36 family practices in Thunder Bay, Ontario. We elicited satisfaction with care for the most recent urgent health problem in the past 6 months on a 7-point scale (very dissatisfied to very satisfied).

RESULTS The response rate was $62.3 \%(5,884$ of 9,397$)$. Of the 5,722 eligible patients $1,342(23.4 \%)$ reported an urgent health problem, and data were available for both services used and satisfaction for 1,227 patients. After adjusting for sociodemographic characteristics and self-reported health status, satisfaction with care received for most recent urgent health problem was significantly higher among patients who visited or spoke to their family physician (mean 6.1; $95 \%$ confidence interval $[\mathrm{Cl}], 5.8-6.4$ ) compared with all other services (all $P<.004$, adjusted for multiple comparisons), with the exception of patients who used the after-hours clinic affiliated with their physician, whose satisfaction was not significantly different (mean 5.6; 95\% Cl, 5.2-6.0).

CONCLUSIONS Satisfaction was highest for patients receiving care from their own family physician or their physician's after-hours clinic. These results are important for new primary care models that emphasize continuity and after-hours availability of family physicians.

Ann Fam Med 2007;5:419-424. 10.1370/afm.704

\section{INTRODUCTION}

$\mathrm{P}$ atient satisfaction is an important outcome of health care services and can affect compliance with medical advice, service utilization, and the clinician-patient relationship. ${ }^{1,2}$ Patients' choice of site for care for perceived urgent health problems is likely to involve a multitude of factors and may, in turn, influence health care system organization and continuity of care. Canada, as have many other countries, has faced a shortage of family physicians for many years. For patients with a family physician, options for addressing acute health problems may include an urgent appointment with their own family physician, an after-hours clinic, a walk-in clinic, a hospital emergency department, or telephone health advisory services. Emergency department costs for minor acute illnesses are much higher than treatment in primary care settings, ${ }^{3}$ and there are concerns about lack of continuity and duplication of services in walk-in clinics. ${ }^{4,5}$ Patients' use of health services other than their family physician's practice is not entirely explained by the urgency of the 
problem or by availability of their family physician. For example, up to $30 \%$ of emergency department visits have been characterized as inappropriate or not urgent. ${ }^{6-8}$ Patients often cite perceived urgency, convenience, and lack of availability of their family physicians as reasons for seeking care at walk-in clinics or emergency departments for issues that are not lifethreatening. ${ }^{9-12}$ Another reason for visiting the emergency department may be the immediate availability of tests and investigations.

Many family physicians in Canada provide care only during regular business hours. As a result, patients in these practices must use other services, such as walk-in clinics or the emergency department, if they require care after-hours for an urgent problem. Some patients have additional options to receive care for urgent health problems from their family physician. In Canada recent restructuring of primary care has introduced extended after-hours access to address patients' needs for care. ${ }^{13}$ In Ontario contractual requirements in some new models of primary care introduced in the past decade require physician groups to staff an after-hours clinic with evening and weekend services, in addition to providing physician backup to a nursestaffed telephone triage service.

To better understand patients' satisfaction with care provided in different settings, we report results of a survey and examine family practice patients' satisfaction with the health services they received for their most recent self-defined urgent health problem.

\section{METHODS}

The study was conducted in Thunder Bay, a city in Northern Ontario with a population of approximately 115,000. Thunder Bay has 1 full-service hospital, including a 24-hour emergency department. Many family physicians in the city have joined primary care reform models introduced in Ontario since the late 1990s, including Family Health Networks and Family Health Groups, both of which have contractual obligations to provide some after-hours care. Other community family physicians practice in the traditional system of fee-for-service with no contractual obligations to provide after-hours services. At the time of this study, there were after-hours clinics affiliated with each Family Health Network and Family Health Group. In both these models, physicians form a virtual group (some may or may not be located in one building) and alternate providing after-hours care (usually from $5 \mathrm{pm}$ to 8 pm several evenings each week and 1 half-day on weekends), as well as provide on-call availability to the nurse-staffed after-hours telephone triage. There were also 5 nonaffiliated walk-in clinics open during regular business hours in addition to evening and weekend hours. Patients in Family Health Network and Family Health Group models who visit their own practice's after-hours clinic may see their physician if he or she is staffing the clinic at that time. In the after-hours clinic, information from the visit is provided to the patient's family physician, as these clinics are extensions of the participating practices. Walk-in clinics in the study community rarely forward information about the visit to the patient's family physician.

In 2005 we conducted by mail a cross-sectional survey of the use of and satisfaction with health services for urgent health problems in the previous 6 months among family practice patients in Thunder Bay. We approached 44 family physicians, of whom 36 agreed to participate: all 8 physicians from the city's single Family Health Network, 16 from the 3 Family Health Groups, and 12 from traditional fee-for-service practices.

In the practices without a patient roster, we used electronic billing data to create the sampling frame. In Family Health Network practices, which have rosters of most patients for the purposes of capitated payment, we used the roster for the sampling frame because it was considered to represent true patients of the practice. The Family Health Network practice roster excluded patients of other physicians who might be seen for specialized services not provided by their own family physician, such as obstetrics or palliative care. The roster is updated by the government at 3month intervals. To minimize the number of questionnaires mailed to patients who were deceased or were no longer part of the practice, the sampling frame was limited to patients older than 1 year who had a visit in the previous year. A random sample of approximately 260 patients was selected from each practice, based on sample size calculations for the main study hypothesis regarding health service utilization by patients of physicians practicing in the 3 different models. A total of 9,612 questionnaires were mailed to patients, and approximately 4 weeks later nonrespondents were mailed a reminder letter and second questionnaire. ${ }^{14}$ If the patient was younger than 17 years, a modified version was addressed to the patient's parent or guardian.

The questionnaire was based on adaptations of questions used in a previous study of emergency department use in Canada ${ }^{15}$ and previously validated surveys for sociodemographic and self-reported health questions. ${ }^{16,17}$ The questionnaire was pilot tested with administrative staff at one of the authors' offices and with several patients of a family practice in Hamilton to check for clarity and face validity of the questions, after which minor modifications were made.

The final questionnaire asked whether the respon- 
dent had experienced an urgent health problem that required immediate care in the previous 6 months. Other questions elicited information about the health services the patient used and satisfaction with care. Sites for care included the family physician, the practice's after-hours clinic (if applicable), the emergency department, a walk-in clinic, and a telephone health advisory service. Patients either visiting or speaking directly to a family physician were considered to have received care from the physician. In addition to the provincial health information telephone line staffed by nurses and available to the general public, Family Health Network and Family Health Group practices have an after-hours telephone triage service for their patients, from 5 pm to 9 a m weekdays and on weekends and holidays. Nurses staff this service, and a participating physician is on call. The questionnaire did not distinguish the type of telephone service used. We asked patients to indicate overall how dissatisfied or satisfied they were with how their most recent emergency was handled by circling the appropriate number on a 7-point scale. (The section of the questionnaire asking about urgent health problems and health services used can be found in the Supplemental Appendix,

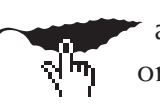
available online-only at http://www.annfammed. org/cgi/content/full/5/419/DC1).

The outcome was mean satisfaction on the 7-point scale. We analyzed the data using analysis of covariance (ANCOVA) and including age (as a continuous variable), sex, highest level of completed education (in school, elementary, some or completed high school, some or completed college or some university, completed university), annual household income $(<\$ 30,000, \$ 30,000-\$ 44,999, \$ 45,000$ $\$ 79,999, \$ 80,000+$ ), self-reported health status (poor, fair, good, very good, excellent) in the model. To account for clustering of patients within physicians, we adjusted the omnibus F test by dividing by the variance inflation factor calculated using the intracluster correlation coefficient for the patient satisfaction outcome. ${ }^{18}$ We present the eta ${ }^{2}$ statistic, the proportion of total variance attributed to the model variables, and calculated post-hoc pairwise comparisons of mean scores at different sites of care. The Bonferroni corrected $P$ value of .004 (0.05/13) was used for these comparisons; otherwise, the criterion of statistical significance was set at $\alpha=.05$. Hedges' $g$ test ${ }^{19}$ was used to assess the effect size of the difference between unadjusted means, calculated using Effect Size Generator, version 2.3. ${ }^{20}$ Analyses were conducted using SPSS version 13.0 (SPSS Inc, Chicago, Ill).

The research ethics boards of Hamilton Health Sciences and the Thunder Bay Regional Health Sciences Center approved the study.

\section{RESULTS}

A total of 9,612 questionnaires were mailed, with 215 patients subsequently excluded because a current correct address could not be found $(n=210)$ or because they were deceased $(n=5)$. Of the remaining 9,397, $62.6 \%(5,884)$ responded. The median response rate per physician was $62.2 \%$ (interquartile range $7.7 \%$ ). The mean age of respondents was 43.8 years (SD 22.2) compared with 36.3 years (SD 20.3) among nonrespondents $(P<.001)$. Respondents were $60.3 \%$ female $(3,549$ of 5,884$)$ compared with $57.5 \%(2,021$ of 3,513$)$ of nonrespondents who were female $(P=.008)$.

Only $1.6 \%$ (97 of 5,884$)$ of respondents indicated that they were not a patient of the physician whose list we sampled or did not answer the question and were thus excluded from the analysis. Sixty-five of the eligible 5,787 respondents did not answer the question about the occurrence of an urgent health problem. Of those who responded, the prevalence of a self-reported urgent health problem in the past 6 months was $23.4 \%$ $(1,342$ of 5,722$)$ (95\% CI, 22.4\%-24.6\%). Among these 1,342 respondents, $97(7.2 \%)$ did not provide information on services used, and a further 18 did not respond to the satisfaction question, leaving 1,227 respondents for analysis. Most respondents $(89.6 \% ; 1,100$ of 1,227) used 1 service, and $10.4 \%$ (127 of 1,227$)$ used 2 or more. Table 1 displays the characteristics of patients who used the different services.

Table 2 displays the mean satisfaction levels for each service, adjusted for the demographic and self-reported health variables, and the $95 \%$ confidence intervals around the mean. The highest satisfaction was reported among patients visiting or speaking to their family physician, followed in descending order by patients who used the after-hours clinic, the emergency department, a telephone health advisory service, a walk-in clinic, and more than 1 service (omnibus ANCOVA $\left.\mathrm{F}_{5,1073}=7.7 ; P<.001 ; \mathrm{eta}^{2}=.05\right)$. Older age and better health status were significant predictors of higher satisfaction. Adjusted mean satisfaction among patients visiting or speaking to the family physician was significantly higher than satisfaction among patients who used the emergency department, a walk-in clinic, a telephone health advisory service, or more than 1 service, but it was not significantly higher than among patients who used their practice's after-hours clinic. Patients who visited their own practice's after-hours clinic were significantly more satisfied than patients who visited a walk-in clinic or used 2 or more services.

A score on the Hedges' $g$ test of less than 0.20 indicates a small effect size, 0.20 to 0.50 indicates a moderate effect size, and 0.50 to 0.80 indicates a large effect size. ${ }^{18}$ Moderate to large effect sizes were found for comparisons of satisfaction for patients visiting 


\begin{tabular}{|c|c|c|c|c|c|c|}
\hline Characteristic & $\begin{array}{l}\text { Family Physician } \\
\qquad(n=201)\end{array}$ & $\begin{array}{l}\text { After-Hours } \\
\text { Clinic } \\
(n=93)\end{array}$ & $\begin{array}{c}\text { Emergency } \\
\text { Department } \\
(n=677)\end{array}$ & $\begin{array}{l}\text { Walk-in } \\
\text { Clinic } \\
(n=94)\end{array}$ & $\begin{array}{c}\text { Telephone } \\
\text { Advisory Service } \\
(\mathrm{n}=35)\end{array}$ & $\begin{array}{l}\text { More Than } \\
1 \text { Service } \\
(\mathrm{n}=127)\end{array}$ \\
\hline Age, mean (SD), y & $47.8,21.0$ & $41.8,24.5$ & $43.4,24.1$ & $38.7,23.7$ & $31.3,25.4$ & $36.6,23.5$ \\
\hline $\begin{array}{l}\text { Proxy respondent for } \\
\text { child }>17 y, \% \text { (n) }\end{array}$ & $12.9(26)$ & $24.7(23)$ & $20.2(137)$ & $25.5(24)$ & $45.7(16)$ & $26.8(34)$ \\
\hline Female, \% (n) & $59.2(119)$ & $70.0(65)$ & $57.3(388)$ & $66.0(62)$ & $71.4(25)$ & $67.7(86)$ \\
\hline Income $\geq \$ 45,000, \%(n)^{*}$ & $54.4(99)$ & $61.8(55)$ & $53.2(322)$ & $65.9(54)$ & $72.7(24)$ & $60.3(70)$ \\
\hline $\begin{array}{l}\text { Some or completed high } \\
\text { school education, } \%(n)^{\dagger}\end{array}$ & $91.3(178)$ & $93.5(87)$ & $88.3(587)$ & $92.2(83)$ & $91.4(32)$ & $96.0(119)$ \\
\hline \multicolumn{7}{|l|}{$\begin{array}{l}\text { Self-reported health } \\
\text { status, } \%(n)^{\ddagger}\end{array}$} \\
\hline Excellent & $15.5(31)$ & $29.0(27)$ & $16.0(107)$ & $25.3(23)$ & $22.9(8)$ & $23.0(29)$ \\
\hline Very good & $36.0(72)$ & $31.2(29)$ & $32.2(215)$ & $34.1(31)$ & $37.1(13)$ & $26.2(33)$ \\
\hline Good & $32.0(64)$ & $28.0(26)$ & $32.5(217)$ & $27.5(25)$ & $28.6(10)$ & $33.3(42)$ \\
\hline Fair & $11.0(22)$ & $8.6(8)$ & $13.6(91)$ & $8.8(8)$ & $5.7(2)$ & $14.3(18)$ \\
\hline Poor & $3.2(4)$ & $3.2(3)$ & $5.7(38)$ & $4.4(4)$ & $5.7(2)$ & $3.2(4)$ \\
\hline
\end{tabular}

Table 2. Adjusted Mean Satisfaction Score for Care for Most Recent Urgent Health Problem Among 1,227 Patients Who Used Different Services

\begin{tabular}{lcc}
\hline Site of Service* & $\begin{array}{c}\text { Adjusted Score } \\
\text { Mean (SE) }\end{array}$ & $\mathbf{9 5 \% ~ C l ~}$ \\
\hline Family physician $^{\ddagger}$ & $6.1(0.14)$ & $5.8-6.4$ \\
After-hours clinic $^{\S}$ & $5.6(0.20)$ & $5.2-6.0$ \\
Emergency department & $5.3(0.08)$ & $5.2-5.5$ \\
Telephone health advisory & $4.8(0.32)$ & $4.2-5.5$ \\
$\quad$ service & $4.7(0.21)$ & $4.3-5.1$ \\
Walk-in clinic & $4.7(0.17)$ & $4.4-5.0$ \\
More than 1 service &
\end{tabular}

Note: Scores are based on a Likert scale in which $7=$ very satisfied, $1=$ very dissatisfied.

$\mathrm{SE}=$ standard error; $\mathrm{Cl}=$ confidence interval.

* For site of care, $\mathrm{F}_{5,1,073}=7.67 ; P<.001$; eta ${ }^{2}=.05$.

† Adjusted for age, sex, self-reported health status, education, and income.

‡ Significantly $(P<.004)$ higher satisfaction compared with patients who used emergency department, walk-in clinic, telephone health advisory service, or more than service.

$\S$ Statistically significantly $(P<.004)$ higher satisfaction compared with patients who used a walkin clinic or more than 1 service.

I Statistically significantly $(P<.004)$ higher satisfaction compared with patients who used more than 1 service.

the family physician vs the emergency department $(g=0.52)$, a walk-in clinic $(g=0.69)$, using a telephone health advisory service $(g=0.65)$, or using 2 or more services $(g=0.70)$. Effects sizes for satisfaction among patients using the after-hours clinic vs a walk-in clinic, a telephone health advisory service, or 2 or more services were moderate $(g=0.49-0.50)$; and effect sizes for patients using the emergency department vs the after-hours clinic, walk-in clinic, a telephone health advisory service, or more than 1 service were low to moderate $(g=0.20-0.23)$.

\section{DISCUSSION}

This study found that patients reporting an urgent health problem who visited their family physician or an after-hours clinic with which their physician was affiliated were most satisfied, and patients who visited their family physician were significantly more satisfied than patients who obtained care at the emergency department or a walk-in clinic, or who used a telephone health advisory service.

Patient satisfaction is influenced to a large extent by expectations. Patients who could not access their own family physician and who had lower expectations of walk-in clinic or emergency department services may account for the lower satisfaction at these sites. Continuity of care, timeliness of care provision, and having expectations met by the family physician have been associated with satisfaction in previous studies. In studies of after-hours care from general practice cooperatives with deputizing services (ie, on-call replacement physicians) and telephone advice, satisfaction was lower for patients who did not receive care from a clinician or in the location that was desired, and satisfaction was lower for deputizing services compared with the usual general practitioners. ${ }^{21-24}$ Some authors suggest this outcome may be due in part to longer wait times for deputizing services. ${ }^{22}$ In previous studies, physician continuity appeared to have inconsistent effects on patient satisfaction. In a study 
of primary care patients consulting their family physician in the United States and the United Kingdom, satisfaction was highest for patients consulting their own doctor if they reported high trust in their doctors. ${ }^{25}$ One study has found that continuity was important for predicting satisfaction only for patients with a high volume of visits, whereas some patients preferred a shorter wait time regardless of physician. ${ }^{26}$

Patients may be more satisfied with waiting times in the family physician's office than in other sites, such as walk-in clinics or emergency departments. ${ }^{27}$ Although we did not have information on the length of time spent waiting, long wait times experienced in the emergency department may partially explain patients' lower satisfaction scores, especially if patients came to the emergency department with less-urgent problems and were triaged to a lower priority of care. In a Canadian study, patients visiting for a defined set of non-life-threatening acute conditions were more satisfied with walk-in clinics than emergency departments. ${ }^{27}$ In the present study, satisfaction was higher for the emergency department than walk-in clinics, although not significantly. This result may be related in part to satisfaction with shorter wait times. The present study included any patients regardless of how acute the problem, and patients with serious problems may have been treated very quickly in the emergency department.

In this study, there was no difference in satisfaction between patients receiving care from their family physician and those receiving care in their physician's group after-hours clinic, and satisfaction was higher for both of these services than for walk-in clinics, suggesting that providing patients with after-hours access to such care may be advantageous. A previous study has found that satisfaction with walk-in clinics and family physicians was similar with respect to patient-centered communication and physician's attitude ${ }^{27}$ In the current study, the chance of seeing one's own physician on-call at the after-hours clinic and the continuity of information between the after-hours clinic visit and the patient's family physician may have contributed to a perception among patients of improved continuity and coordination, leading to higher satisfaction when compared with walk-in clinics.

Older age and better self-reported health status were associated with higher satisfaction independent of the site in which care was received. Older patients may have experienced more serious health problems and appreciated more the care they received, they may have had lower expectations, or they may have received quicker access to care. Other studies have also reported older patients to be more satisfied with primary care ${ }^{28}$ and after-hours care ${ }^{22}$ than younger patients.
Satisfaction with telephone health advisory services was lower than for nearly all other services and was significantly lower than for patients receiving care from the family physician. A previous study of after-hours telephone health advisory service in Ontario found that most callers were advised to seek additional care or advice from a health care clinician. ${ }^{29}$ In this study, if patients' concerns were not completely addressed by the telephone advisory service, being required to seek additional care may explain their lower satisfaction.

There are several limitations in this study. The time lag of up to 6 months between the urgent problem and the questionnaire administration is a limitation and may have affected reliability of the responses, because patients' perceptions of their experiences may have changed compared with their perceptions immediately after seeking care. In addition, we did not have information on the nature or severity of the problem for which patients sought care, which may have been a potential confounder of the association between site of care chosen and satisfaction with the outcome of care. The proportion of variance explained by the type of service used was very small and suggests other factors contributed to satisfaction. We did not have information about whether patients who used a nurse-staffed telephone health advisory service had subsequent contact with a physician when they were part of a practice model that had physician back-up to the telephone service, and satisfaction may have been different for telephone advice alone vs contact with the on-call physician. Our questionnaire contained only 1 question on satisfaction and did not address the various domains that have been incorporated into other surveys, such as satisfaction with access, communication, physician's attitude, and outcomes of care. ${ }^{21,27,28}$ Overall satisfaction, however, has been shown to have a moderate to high correlation with other related concepts of care, such as communication, trust, technical care, and interpersonal skills of the physician. ${ }^{30}$

In future research it would be helpful to examine patient satisfaction for urgent health problems in other geographic areas and different primary care systems. Future research could benefit from a more comprehensive satisfaction instrument that assesses satisfaction with wait times, communication with and attitude of the physician, and satisfaction with the outcome of care in a study that accounts for level of care expectations and the nature and severity of the problem. Such information could also be used to inform quality indicators. In settings with relatively new nurse-staffed telephone health advisory systems, it would be important to evaluate the use of and satisfaction with these services in more detail.

The new models of primary care in Ontario and 
in many other provinces and countries emphasize improved access and continuity for patients. Satisfaction may be one important factor in determining what services patients choose for urgent unscheduled encounters with the health care system. The finding that patients are most satisfied receiving care for a self-defined urgent health problem from their own physician or an after-hours clinic staffed in part by their own physician supports increasing financial and human resources to enhanced access to practice-based primary care services.

To read or post commentaries in response to this article, see it online at http://www.annfammed.org/cgi/content/full/5/5/419.

Key words: Patient satisfaction; family practice; emergency service, hospital; walk-in clinics; ambulatory care facilities; telephone triage; urgent care; after-hours care

Submitted November 3, 2006; submitted, revised, February 12, 2007; accepted March 17, 2007.

Funding support: This study was supported by the Ontario Ministry of Health and Long-Term Care, Primary Health Care Transition Fund grant No. G03-02775.

Disclaimer: The views expressed in this paper are those of the authors and do not reflect the views of the Ontario Ministry of Health and Long-Term Care.

\section{References}

1. Kahan B, Goodstadt M. Continuous quality improvement and health promotion: Can CQI lead to better outcomes? Health Prom Intl. 1999;14(1):83-91.

2. Hjortdahl P, Laerum E. Continuity of care in general practice: effect on patient satisfaction. BMJ. 1992;304(6837):1287-1290.

3. Campbell MK, Silver RW, Hoch JS, et al. Re-utilization outcomes and costs of minor acute illness treated at family physician offices, walk-in clinics, and emergency departments. Can Fam Physician. 2005; $51: 82-83$

4. Bell N, Szafran O. Use of walk-in clinics by family practice patients. Can Fam Physician. 1992;38:507-513.

5. Jones M. Walk-in primary medical care centres: lessons from Canada. BMJ. 2000;321(7266):928-931.

6. Martin A, Martin C, Martin PB, Martin PA, Green G, Eldridge $S$. 'Inappropriate' attendance at an accident and emergency department by adults registered in local general practices: how is it related to their use of primary care? J Health Serv Res Policy. 2002;7(3):160-165.

7. Afilalo J, Marinovich A, Afilalo M, et al. Nonurgent emergency department patient characteristics and barriers to primary care. Acad Emerg Med. 2004;11(12):1302-1310.

8. Vertesi L. Does the Canadian Emergency Department Triage and Acuity Scale identify non-urgent patients who can be triaged away from the emergency department? CJEM. 2004;6(5):337-342.

9. Burnett MG, Grover SA. Use of the emergency department for nonurgent care during regular business hours. CMAJ. 1996;154(9): 1345-1351.
10. Boushy D, Dubinsky I. Primary care physician and patient factors that result in patients seeking emergency care in a hospital setting: the patient's perspective. J Emerg Med. 1999;17(3):405-412.

11. Szafran O, Bell NR. Use of walk-in clinics by rural and urban patients. Can Fam Physician. 2000;46:114-119.

12. Miller G, Mah Z, Nantes S, Bryant W, Kayler T, McKinnon K. Walk-in clinics: a preliminary descriptive study. Can Fam Physician. 1989;35:2013-2015.

13. Primary care reform - A national overview. Canadian Medical Association. 2006. http://www cma.ca/Multimedia/CMA/Content_Images/Inside_cma/WhatWePublish/LeadershipSeries/English/ national_overview.pdf.

14. Dillman D. Mail and Telephone Surveys. The Total Design Method. Toronto: John Wiley \& Sons; 1978.

15. Grad R, Kaczorowski J, Singer Y, Levitt C, Mandelcorn J. Where do family practice patients go in case of emergency? Can Fam Physician. 1998;44:2666-2672

16. Ware JE, Jr., Sherbourne CD. The MOS 36 -item short-form health survey (SF-36). I. Conceptual framework and item selection. Med Care. 1992;30(6):473-483.

17. Statistics Canada. 2007. http://www.statcan.ca.

18. Skinner C, Holt D, Smith T. Analysis of Complex Surveys. New York, NY: John Wiley \& Sons Inc; 1989.

19. Hedges L. Estimation of effect size from a series of independent experiments. Psychol Bull. 1982;92(2)::490-499.

20. Devilly G]. The Effect Size Generator for Windows: Version 2.3 [com puter program]. Centre for Neuropsychology, Swinburne University, Australia; 2004. http://www.swin.edu.au/victims/resources/software/ effectsize/effect_size_generator.html. Accessed June 13, 2006.

21. McKinley RK, Manku-Scott T, Hastings AM, French DP, Baker R. Reliability and validity of a new measure of patient satisfaction with out of hours primary medical care in the United Kingdom: development of a patient questionnaire. BMJ. 1997;314(7075):193-198.

22. McKinley RK, Roberts C. Patient satisfaction with out of hours primary medical care. Qual Health Care. 2001;10(1):23-28.

23. McKinley RK, Stevenson K, Adams S, Manku-Scott TK. Meeting patient expectations of care: the major determinant of satisfaction with out-of-hours primary medical care? Fam Pract. 2002;19(4): 333-338.

24. Salisbury C. Postal survey of patients' satisfaction with a general practice out of hours cooperative. BMJ. 1997;314(7094):1594-1598.

25. Baker R, Mainous AG, 3rd, Gray DP, Love MM. Exploration of the relationship between continuity, trust in regular doctors and patient satisfaction with consultations with family doctors. Scand J Prim Health Care. 2003;21(1):27-32.

26. Morgan ED, Pasquarella M, Holman JR. Continuity of care and patient satisfaction in a family practice clinic. J Am Board Fam Pract. 2004;17(5):341-346.

27. Hutchison B, Ostbye T, Barnsley J, et al. Patient satisfaction and quality of care in walk-in clinics, family practices and emergency departments: the Ontario Walk-In Clinic Study. CMAJ. 2003;168(8):977-983.

28. Bikker AP, Thompson AG. Predicting and comparing patient satisfaction in four different modes of health care across a nation. Soc Sci Med. 2006;63(6):1671-1683.

29. Price Waterhouse Coopers Evaluation of Primary Care Reform Pilots - Phase 1 Final Report. Ontario, Canada: Government of Ontario; 2001

30. Ramsay J, Campbell JL, Schroter S, Green J, Roland M. The General Practice Assessment Survey (GPAS): tests of data quality and measurement properties. Fam Pract. 2000;17(5):372-379. 